\title{
Obstructive Ileocolitis in Patients With Obstructed Colorectal Cancer - A Matched Case Control Study
}

\author{
Ning-Qi Pang, Tian-Zhi Lim, Yuanpei Zhou, Ker-Kan Tan \\ Division of Colorectal Surgery, University Surgical Cluster, National University Health System, Singapore
}

Purpose: Obstructive ileocolitis is an ulcero-inflammatory condition which typically occurs in the ileum or colon proximal to an obstructing colorectal lesion. If left unresolved, it often leads to intestinal perforation. We present a matched case control study of patients with obstructive ileocolitis caused by colorectal cancer to determine if any factors can predict this condition.

Methods: This is a retrospective review of 21 patients with obstructive colorectal cancer and histologically proven obstructive ileocolitis from 2005 to 2015 matched for age and sex with 21 controls with obstructing colorectal cancer without obstructive ileocolitis.

Results: The 21 patients with obstructive ileocolitis had a median age of 71 years (range, 52-86 years). The most common presenting symptom was abdominal pain $(\mathrm{n}=16,76.2 \%)$, followed by vomiting/nausea $(\mathrm{n}=14,66.7 \%)$ and abdominal distension $(n=12,57.1 \%)$. Interestingly, the radiological feature of pneumatosis intestinalis was noted in only 1 case. No significant differences were observed in baseline comorbidities, clinical presentations, or tumor characteristics between the 2 groups. Patients with obstructive ileocolitis were found to have a significantly higher total leucocyte count (17.1 \pm $9.4 \times 10^{9} / \mathrm{L}$ vs. $\left.12.0 \pm 6.8 \times 10^{9} / \mathrm{L}, \mathrm{P}=0.016\right)$, lower $\mathrm{pCO}_{2}(32.3 \pm 8.2 \mathrm{mmHg}$ vs. $34.8 \pm 4.9 \mathrm{mmHg}, \mathrm{P}=0.013)$, lower $\mathrm{HCO}_{3}$ $(18.8 \pm 4.5 \mathrm{mmol} / \mathrm{L}$ vs. $23.6 \pm 2.7 \mathrm{mmol} / \mathrm{L}, \mathrm{P}<0.001)$, lower base excess $(-6.53 \pm 5.32 \mathrm{mmol} / \mathrm{L}$ vs. $-0.57 \pm 2.99 \mathrm{mmol} / \mathrm{L}, \mathrm{P}$ $<0.001)$ and higher serum lactate levels $(3.14 \pm 2.19 \mathrm{mmol} / \mathrm{L}$ vs. $1.19 \pm 0.91 \mathrm{mmol} / \mathrm{L}, \mathrm{P}=0.007)$ compared to controls. No radiological features were predictive of obstructive ileocolitis.

Conclusion: Patients with obstructive ileocolitis tend to present with metabolic acidosis with respiratory compensation, raised lactate, and worse leucocytosis. Radiological features are not useful for predicting this condition.

Keywords: Colorectal cancer; Intestinal obstruction; Obstructive ileocolitis

\section{INTRODUCTION}

Obstructive ileocolitis is an ulcero-inflammatory lesion proximal to an obstructive colorectal lesion [1]. As the name implies, both the ileum and colon can be involved in this condition. Excessive

Received: February 20,2017 • Accepted: June 14, 2017

Correspondence to: Ker-Kan Tan, MBBS, FRCS

Division of Colorectal Surgery, University Surgical Cluster, National University Hospital, 1E, Kent Ridge Road, NUHS Tower Block, Level 8, Singapore 119228, Singapore

Tel: +65-6779-5555, Fax: +65-6777-8206

E-mail: ker_kan_tan@nuhs.edu.sg

ORCID code: https://orcid.org/0000-0002-0410-0450

(C) 2018 The Korean Society of Coloproctology

This is an open-access article distributed under the terms of the Creative Commons Attribution NonCommercial License (http://creativecommons.org/licenses/by-nc/4.0) which permits unrestricted noncommercial use, distribution, and reproduction in any medium, provided the original work is properly cited. pressure due to distension of the bowel leading to ischemia has been proposed as the possible underlying pathophysiologic process [2]. Not surprisingly, the cecum is the most likely location at which this condition often manifests itself [3]. Ulcero-inflammatory lesions can take the form of ulcers, perforations or features of ischemia, such as gangrene.

When obstructive ileocolitis presents itself, management to relieve the obstruction should be initiated immediately as further delays could result in worsening ischemia and eventual perforation, which increases perioperative morbidity and mortality significantly [4]. Therefore, a need exists to identify these patients early and to expedite interventions to relieve the obstruction. The aim of this study was to identify factors that could be associated with obstructive ileocolitis by matching patients with obstructed colorectal cancer with obstructive ileocolitis with a similar cohort of patients with obstructed colorectal cancers but without obstructive ileocolitis. 


\section{METHODS}

Between November 2005 to June 2015, 21 patients (cases) with obstructive ileocolitis presented with intestinal obstruction secondary to colorectal cancers Obstructive ileocolitis was defined as histologic findings of ulcers, ischemia, gangrene or perforations of either the large or the small bowel. These cases were then matched on a 1:1 ratio for age and gender to patients with obstructed colorectal cancers but without obstructive ileocolitis (the controls). In the controls, the mucosa linings of the proximal colon were devoid of the aforementioned pathological features. This study was approved by the Institutional Review Board of the National University of Singapore. In view of the retrospective nature of this study, informed consent was deemed unnecessary by the Institutional Review Board.

Patient demographics, clinical findings on history taking and examination, and the results of pre-operative blood tests and radiological investigations were documented. Results were analyzed using Stata version 13.0, and $\mathrm{P}<0.05$ was considered statistically significant. Univariate analyses were performed using the Wilcoxon matched-pairs signed-ranked test and the paired t-test for continuous variables and McNemar's exact test for categorical variables.

Table 1. Comparison of patients' characteristics between cases and controls

\begin{tabular}{lccc}
\hline Characteristic & $\begin{array}{c}\text { Case } \\
(\mathrm{n}=21)\end{array}$ & $\begin{array}{c}\text { Control } \\
(\mathrm{n}=21)\end{array}$ & P-value \\
\hline Age (yr) & $71(52-86)$ & $68(50-87)$ & - \\
Sex & & & - \\
$\quad$ Male & $10(47.6)$ & $10(47.6)$ & \\
Female & $11(52.4)$ & $11(52.4)$ & \\
Ethnicity & & & - \\
Chinese & $10(47.6)$ & $19(90.5)$ & \\
Malay & $8(38.1)$ & $2(9.5)$ & \\
Indian & $0(0)$ & $0(0)$ & \\
Others & $3(14.3)$ & $0(0)$ & \\
Patient comorbidities & & & \\
Diabetes mellitus & $7(33.3)$ & $5(23.8)$ & 0.774 \\
Hypertension & $12(57.1)$ & $10(47.6)$ & 0.754 \\
Hyperlipidemia & $10(47.6)$ & $7(33.3)$ & 0.607 \\
Stroke & $3(14.3)$ & $0(0)$ & 0.250 \\
Ischemic heart disease & $3(14.3)$ & $5(23.8)$ & 0.625 \\
Colonic diverticulum & $0(0)$ & $1(4.8)$ & 0.999 \\
Previous abdominal surgery & $3(14.3)$ & $3(15.0)$ & 0.999 \\
Smoker & $2(12.5)$ & $2(20.0)$ & 0.999 \\
\hline
\end{tabular}

Values are presented as median (range) or number (\%).

\section{RESULTS}

The 21 patients identified with obstructive ileocolitis had a median age of 71 years (range, 52-86 years). About half of these patients had hypertension (57.1\%) and hyperlipidemia (47.6\%), with one-third suffering from diabetes $(33.3 \%)$. The most common presenting symptom was abdominal pain (76.2\%), followed by vomiting/nausea (66.7\%), and abdominal distension $(57.1 \%)$. Table 1 shows the general profile of our study population. The location of abdominal pain appears to be varied, with roughly equal numbers of patients complaining of pain in the various quadrants of the abdomen, as shown in Table 2. Cases also generally presented with normal hemodynamic parameters and were afebrile $\left(36.9^{\circ} \mathrm{C} \pm 0.8^{\circ} \mathrm{C}\right)$. Cases were found to have a shorter time from scan to surgery $(\mathrm{P}=0.046)$. This is likely a reflection of the prioritization given to them by the medical team for early surgery in

Table 2. Comparison of clinical presentations between cases and controls

\begin{tabular}{lccc}
\hline Variable & $\begin{array}{c}\text { Case } \\
(\mathrm{n}=21)\end{array}$ & $\begin{array}{c}\text { Control } \\
(\mathrm{n}=21)\end{array}$ & P-value \\
\hline Duration of symptoms (day) & $3.5(2.5-6)$ & $4(2-14)$ & 0.549 \\
Symptoms & & & \\
\hline Abdominal pain & $16(76.2)$ & $18(85.7)$ & 0.727 \\
\hline Vomiting/nausea & $14(66.7)$ & $12(57.1)$ & 0.999 \\
\hline Abdominal distension & $12(57.1)$ & $16(76.2)$ & 0.219 \\
\hline Constipation & $11(52.4)$ & $12(57.1)$ & 0.625 \\
\hline Rectal bleeding & $1(4.8)$ & $1(4.8)$ & 0.999 \\
\hline Location of abdominal pain & & & \\
\hline Generalized & $7(33.3)$ & $7(33.3)$ & 0.999 \\
\hline Epigastrium & $9(42.9)$ & $10(47.6)$ & 0.999 \\
Right iliac fossa & $9(42.9)$ & $10(47.6)$ & 0.774 \\
\hline Left iliac fossa & $8(38.1)$ & $13(61.9)$ & 0.180 \\
\hline Left hypochondrium & $8(38.1)$ & $8(38.1)$ & 0.999 \\
\hline Umbilical & $9(42.9)$ & $8(38.1)$ & 0.999 \\
\hline Parameters & & & \\
\hline Systolic blood pressure & $130.4 \pm 37.9$ & $132.9 \pm 16.8$ & 0.718 \\
\hline Diastolic blood pressure & $70.3 \pm 15.4$ & $77.0 \pm 9.4$ & 0.141 \\
\hline Heart rate & $91.2 \pm 20.1$ & $90.1 \pm 11.8$ & 0.794 \\
\hline Respiratory rate & $17.7 \pm 1.2$ & $17.8 \pm 1.1$ & 0.600 \\
\hline Temperature & $36.9 \pm 0.8$ & $36.7 \pm 0.6$ & 0.388 \\
\hline Neo-adjuvant chemoradiotherapy & $9.3 \pm 5.9$ & $28.8 \pm 27.5$ & 0.046 \\
\hline Preoperative chemotherapy & $1(4.8)$ & $0(0)$ & 0.999 \\
\hline Preoperative radiotherapy & $0(0)$ & $0(0)$ & 0.999 \\
\hline Valus are presented as mean to surgery (hr) & & & \\
\hline & & & \\
\hline
\end{tabular}

Values are presented as median (interquartile range), number (\%), or mean \pm standard deviation. 
view of an impending perforation as evidenced by high lactate and metabolic acidosis. Table 3 shows that cases of obstructive ileocolitis had elevated total leucocyte count $\left(17.1 \pm 9.4 \times 10^{9} / \mathrm{L}\right)$. Arterial blood gas analyses revealed low standardized bicarbonate $(18.8 \pm 4.5 \mathrm{mmol} / \mathrm{L})$, low base excess $(-6.53 \pm 5.32 \mathrm{mmol} / \mathrm{L})$, and high lactate $(3.14 \pm 2.19 \mathrm{mmol} / \mathrm{L})$. Radiological features of proximal bowel dilatation, collapsed distal bowel, and small bowel involvement were present in over half of these cases.

When the 21 cases were compared against the controls, no significant differences were observed in the prevalence of comorbidities, such as hypertension, diabetes or hyperlipidemia. In addition, no significant differences in the duration of symptoms prior to presentation to the hospital were noted. Moreover, no specific symptoms or location of abdominal pain was associated with a higher likelihood of developing obstructive ileocolitis. Traditional vital signs, such as heart rate, temperature and blood pressure, were also not predictive of obstructive ileocolitis. Compared to the controls, cases were found to have a significantly higher total leucocyte count $\left(17.1 \pm 9.4 \times 10^{9} / \mathrm{L}\right.$ vs. $\left.12.0 \pm 6.8 \times 10^{9} / \mathrm{L}, \mathrm{P}=0.016\right)$, lower $\mathrm{pCO}_{2}(32.3 \pm 8.2 \mathrm{mmHg}$ vs. $34.8 \pm 4.9 \mathrm{mmHg}, \mathrm{P}=0.013)$, lower $\mathrm{HCO}_{3}(18.8 \pm 4.5 \mathrm{mmol} / \mathrm{L}$ vs. $23.6 \pm 2.7 \mathrm{mmol} / \mathrm{L}, \mathrm{P}<$ $0.001)$, lower base excess $(-6.53 \pm 5.32 \mathrm{mmol} / \mathrm{L}$ vs. $-0.57 \pm 2.99$

Table 3. Comparison of laboratory parameters and computed tomography features between cases and controls

\begin{tabular}{|c|c|c|c|}
\hline Variable & $\begin{array}{c}\text { Case } \\
(n=21)\end{array}$ & $\begin{array}{l}\text { Control } \\
(n=21)\end{array}$ & P-value \\
\hline Hemoglobin (g/dL) & $11.3 \pm 3.0$ & $11.6 \pm 2.7$ & 0.627 \\
\hline Hematocrit (\%) & $34.9 \pm 7.8$ & $35.3 \pm 6.4$ & 0.718 \\
\hline Total leucocyte count $\left(\times 10^{9} / \mathrm{L}\right)$ & $17.1 \pm 9.4$ & $12.0 \pm 6.8$ & 0.016 \\
\hline Platelets $\left(\times 10^{9} / \mathrm{L}\right)$ & $406.6 \pm 128.8$ & $367.8 \pm 117.3$ & 0.387 \\
\hline Urea (mmol/L) & $8.6 \pm 5.9$ & $7.2 \pm 7.8$ & 0.549 \\
\hline Creatinine ( $\mu \mathrm{mol} / \mathrm{L})$ & $133.6 \pm 149.9$ & $76.2 \pm 33.0$ & 0.105 \\
\hline Carcinogen embryonic antigen ( $\mu \mathrm{g} / \mathrm{L})$ & $30.7 \pm 37.3$ & $252.4 \pm 540.7$ & 0.193 \\
\hline $\mathrm{pH}$ & $7.37 \pm 0.10$ & $7.17 \pm 0.87$ & 0.538 \\
\hline $\mathrm{pCO}_{2}(\mathrm{mmHg})$ & $32.3 \pm 8.2$ & $34.8 \pm 4.9$ & 0.013 \\
\hline $\mathrm{HCO}_{3}$ (standard) (mmol/L) & $18.8 \pm 4.5$ & $23.6 \pm 2.7$ & $<0.001$ \\
\hline Base excess (mmol/L) & $-6.53 \pm 5.32$ & $-0.57 \pm 2.99$ & $<0.001$ \\
\hline Lactate (mmol/L) & $3.14 \pm 2.19$ & $1.19 \pm 0.91$ & 0.007 \\
\hline Glucose (mmol/L) & $8.4 \pm 3.0$ & $7.2 \pm 1.9$ & 0.072 \\
\hline \multicolumn{4}{|l|}{ CT evidence of } \\
\hline Proximal bowel dilatation & $16(76.2)$ & $20(95.2)$ & 0.250 \\
\hline Cecal wall oedema/pneumatosis & $2(9.5)$ & $2(9.5)$ & 0.999 \\
\hline Collapsed bowel distally & $13(61.9)$ & $8(38.1)$ & 0.289 \\
\hline Small bowel involvement & $12(57.1)$ & $14(66.7)$ & 0.375 \\
\hline Closed loop & $2(9.5)$ & $6(28.6)$ & 0.625 \\
\hline Metastatic disease & $3(14.3)$ & $1(4.8)$ & 0.999 \\
\hline
\end{tabular}

Values are presented as mean \pm standard deviation or number (\%). $\mathrm{mmol} / \mathrm{L}, \mathrm{P}<0.001)$ and higher lactate $(3.14 \pm 2.19 \mathrm{mmol} / \mathrm{L}$ vs $1.19 \pm 0.91 \mathrm{mmol} / \mathrm{L}, \mathrm{P}=0.007$ ) (Table 3). No radiological features were noted to be predictive of obstructive ileocolitis.

Table 4 shows our study population's tumor characteristics as reported on histology. No statistically significant differences were found. Most of our cases of obstructive ileocolitis had ulceration noted on histology $(76.2 \%)$, half had evidence of bowel ischemia (52.4\%), and only 1 (4.8\%) presented with perforation. Table 5 shows the Clavien-Dindo classification of cases compared to controls. Interestingly, 4 deaths occurred among the controls compared to none among cases, although drawing any significant conclusion is difficult as the study was not designed for this comparison.

Table 4. Comparison of the tumors' characteristics between cases and controls

\begin{tabular}{|c|c|c|c|}
\hline Variable & $\begin{array}{c}\text { Case } \\
(n=21)\end{array}$ & $\begin{array}{l}\text { Control } \\
(n=21)\end{array}$ & P-value \\
\hline Tumor locationa) & & & - \\
\hline Right colon & $9(42.9)$ & $12(57.1)$ & \\
\hline Left colon & $9(42.9)$ & $9(42.9)$ & \\
\hline Rectum & $3(14.3)$ & $0(0)$ & \\
\hline Tumor size (cm) & $4.65 \pm 1.43$ & $4.96 \pm 1.94$ & 0.697 \\
\hline T stage & & & - \\
\hline 4 & $11(52.4)$ & $11(52.4)$ & \\
\hline 3 & $9(42.9)$ & $9(42.9)$ & \\
\hline 2 & $0(0)$ & $0(0)$ & \\
\hline 1 & $0(0)$ & $0(0)$ & \\
\hline N stage & & & - \\
\hline 2 & $7(33.3)$ & $6(28.6)$ & \\
\hline 1 & $7(33.3)$ & $8(38.1)$ & \\
\hline 0 & $6(28.6)$ & $6(28.6)$ & \\
\hline Metastatic disease & $3(14.3)$ & $4(19.0)$ & 0.999 \\
\hline Colon maximum diameter $(\mathrm{cm})^{*}$ & $12.3 \pm 3.9$ & $8.6 \pm 3.6$ & 0.080 \\
\hline Obstructive ileocolitis in & & & - \\
\hline Small bowel & $4(19.0)$ & NA & \\
\hline Large bowel & $17(81.0)$ & - & \\
\hline Obstructive ileocolitis with & & & - \\
\hline Proximal bowel ulceration & $16(76.2)$ & NA & \\
\hline Proximal bowel ischemia & $11(52.4)$ & NA & \\
\hline Proximal bowel perforation & $1(4.8)$ & NA & \\
\hline Ischemia at caecum & $4(19.0)$ & NA & \\
\hline Perforation at caecum & $1(4.8)$ & NA & \\
\hline
\end{tabular}

Values are presented as number (\%) or mean \pm standard deviation.

NA, not available.

a)Right colon, cecum to transverse colon; left colon, splenic flexure to sigmoid colon. 
Table 5. Comparison of surgical complications between cases and controls

\begin{tabular}{lcc}
\hline Clavien-Dindo classification & $\begin{array}{c}\text { Case } \\
(\mathrm{n}=21)\end{array}$ & $\begin{array}{c}\text { Control } \\
(\mathrm{n}=21)\end{array}$ \\
\hline No complications & $15(71.4)$ & $13(61.9)$ \\
I & $4(19.0)$ & $3(14.3)$ \\
II & $0(0)$ & $1(4.8)$ \\
III & $1(4.8)$ & $0(0)$ \\
IV & $1(4.8)$ & $0(0)$ \\
V & $0(0)$ & $4(19.0)$ \\
\hline
\end{tabular}

Values are presented as number (\%).

\section{DISCUSSION}

Our findings suggest that laboratory investigations are perhaps the most useful factor in identifying patients with obstructive ileocolitis when presenting with obstructed colorectal cancer. Interestingly, radiological findings were not associated with obstructive ileocolitis. The presence of high serum lactate, metabolic acidosis with respiratory compensation, and higher leukocytosis were associated with obstructive ileocolitis. Not surprisingly, raised serum lactate with associated metabolic acidosis is also seen in patients with an ischemic bowel [5]. This would suggest a similar pathophysiology that would account for the clinical and the biochemical features seen in obstructive ileocolitis. In essence, the decreased tissue perfusion leads to increased anaerobic respiration, which then results in increased formation of lactic acid from pyruvate. Intestinal injury occurs when a persistently low tissue perfusion state leads to insufficient delivery of oxygen and nutrients required for cellular metabolism. This can be exacerbated by reperfusion injury, a complex response characterized by the release of free radicals and toxic by-products of ischemic injury. In the acute state, respiratory compensation of metabolic acidosis occurs by hyperventilation in a bid to reduce $\mathrm{PaCO}_{2}$.

Moving away from biochemical investigations, computed tomographic scans are commonplace and have become indispensable in the field of surgical practice. Interestingly, in our small series, computed tomography scans did not appear to be helpful in identifying patients with obstructive ileocolitis. This could be because the ulcero-inflammatory changes that underlie the pathogenesis of obstructive ileocolitis start at the tissue level, a level too small in scale to be picked up by radiological imaging and/or because obvious radiological features such as pneumatosis intestinalis take time to develop. Certain radiological features, such as poor enhancement of the bowel wall in the clinical context of metabolic acidosis with high lactate, should still alert the clinician to the possibility of an ischemic bowel, which can occur in cases of obstructive ileocolitis. However, the authors urge caution in interpreting all cases of pneumatosis intestinalis as definite evidence of an ischemic bowel as our earlier publication disputed this rela- tionship [6]. To our knowledge, no prior study has conclusively proven that obstructive ileocolitis can be treated conservatively. Hence, when obstructive ileocolitis is suspected, appropriate and expeditious intervention should be adopted to relieve the obstruction. Should the ischemia continue to worsen, gangrene will likely occur, and perforation is inevitable. Surgery in such instances is fraught with abysmal morbidity and mortality rates.

The authors recognize that this study has several limitations, with main issues being that the small size of the studied population and the biases associated with a retrospective review. However, we hope that these biases were mitigated by our matching the cases with appropriate controls. The varied timings at which the radiological and serological investigations occurred were also not controlled. Moving ahead, as the interest in endoscopic stenting and minimally invasive surgery to relieve an obstruction continues to gain in popularity, an ongoing need exists to verify our findings in future larger scale studies. Only then can we initiate expeditious interventions to relieve obstructions in those at significant risks of developing worsening ischemia and ensuing perforation.

In summary, patients presenting with obstructed colorectal cancers with high lactate and metabolic acidosis with respiratory compensation should be suspected of harboring underlying obstructive ileocolitis. In these patients, expeditious relief of the obstruction is critical.

\section{CONFLICT OF INTEREST}

No potential conflict of interest relevant to this article was reported.

\section{ACKNOWLEDGMENTS}

The authors would like to thank Associate Professor Tai Bee Choo from the Saw Swee Hock School of Public Health for her invaluable advice during this project.

\section{REFERENCES}

1. Harada T, Umezawa I, Mogami K, Itoh Z. Acute gangrenous colitis proximal to obstructive cancer of the sigmoid colon. Jpn J Surg 1975;5:39-47.

2. Toner M, Condell D, O'Briain DS. Obstructive colitis. Ulceroinflammatory lesions occurring proximal to colonic obstruction. Am J Surg Pathol 1990;14:719-28.

3. Stillwell GK. The law of laplace. Some clinical applications. Mayo Clin Proc 1973;48:863-9.

4. Chen HS, Sheen-Chen SM. Obstruction and perforation in colorectal adenocarcinoma: an analysis of prognosis and current trends. Surgery 2000;127:370-6.

5. Studer P, Vaucher A, Candinas D, Schnüriger B. The value of serial serum lactate measurements in predicting the extent of ischemic bowel and outcome of patients suffering acute mesenteric 
ischemia. J Gastrointest Surg 2015;19:751-5.

6. Ngu J, Lieske B, Chan KH, Lim TZ, Cheong WK, Tan KK. Caecal pneumatosis is not an absolute contraindication for endoluminal stenting in patients with acute malignant large bowel obstruction. ANZ J Surg 2014;84:772-5. 